The Relationship of Clinician Demographic Variables to Discipline Board Misconduct Content 


\begin{abstract}
This study was designed as an investigation of clinician variables that correlate with the contents of findings of misconduct. While there is a scarcity of current research regarding clinician characteristics that correlate with professional misconduct, many assumptions and untested hypotheses appear. In particular, gender is often identified as a critical component of professional misconduct. Despite these common assertions, virtually no published research exists regarding correlations between gender and marriage and family therapist (MFT) professional misconduct. This study employed a retrospective cross-sectional study to analyze a randomized convenience sample of the records of final determinations of clinician disciplinary actions across eight states. Four control variables (gender, years of experience, geographical region, and type of license) were correlated with six criterion variables consisting of word counts for six linguistic categories (family, substance, finance, sex, friend, and recordkeeping words). Frequency rates of the criterion variables were calculated. Relationships between all variables were evaluated through a multiple linear regression analysis. The data show a wide variation of prevalence rates across the control variables. Four of the multiple regression analyses produced statistically significant results. Gender was related to both family and finance related words, while years of practice was related to family, finance, sex, friend, and recordkeeping words. No relationship was found between recordkeeping words and any of the control variables. Similarly, no relationship was found between any of the criterion variables and geographic region or license type. Keywords: ethics, gender, misconduct, professional discipline, corpus linguistics. LIWC, counseling, marriage and family therapy, social work
\end{abstract}




\section{The Relationship of Clinician Demographic Variables to Discipline Board Misconduct Content}

Despite many popular cultural references to the contrary, masters degree level clinicians are neither all saints nor all predators. Still, a significant number of clinicians receive sanctions for engaging in professional misconduct. An investigation into the degree to which personal, professional, and regional demographics are meaningful in separating these sanctioned professionals from the unsanctioned whole guided the present study.

Empirically identifying whether or not there are relationships between clinician professional misconduct and personal and professional demographics is necessary to better understand types and contexts of professional misconduct in order to effectively and efficiently educate, develop, and supervise clinicians (Coy et al., 2016; Evan \& Robinson, 2013). Moreover, since systematic studies of clinician gender and misconduct, particularly with regard to marriage and family therapists, are virtually non-existent, current research into this topic is needed to better understand professional misconduct as it actually occurs (Sonne \& Jochai, 2014).

To contextualize this study, a review of the existing literature will follow that includes: (a) definition of terms related to professional licensure, (b) gender demographics of licensure type, (c) some common assumptions found in the literature regarding clinician gender and misconduct, (d) a discussion of Pope et al.'s (1979) seminal study on sexual misconduct committed by psychologists, and (e) what is known about clinician gender demographics that correlate with professional misconduct. Finally, the research questions will be presented.

State regulatory boards use a variety of terms to describe the clinical professions of marriage and family therapy, social work, and licensed counseling. In each of these disciplines the master's degree is considered the entry degree. In this study, the following definitions apply. The term marriage and family therapy refers to the credentialed practice of marriage and family therapy, clinical marriage and family therapy, or other similarly-labeled clinical practice. The term social work refers to the 
credentialed practice of social work, clinical social work, independent social work, advanced practice social work, specialist clinical social work, master's level social work, or other similarly-labeled clinical practice. The term licensed counseling refers to the credentialed practice of mental health counseling, professional counseling, professional clinical counseling, or other similarly-labeled clinical practice. The terms clinician is used as a generic term to refer to social workers, licensed counselors, and marriage and family therapists. As with licensure nomenclature, there is great complexity in the literature regarding the relationship between gender and professional misconduct.

With regard to gender, the clinical professions were at one time male dominated (Willyard, 2011). More recently, however, this field has moved towards more inclusivity with a wider range of clinician gender identities (Meyers, 2017; Michel et al., 2013; Shipman, 2019). Contrary to this increasing scope of gender identities within the clinical professions, gender statistics compiled by federal and state regulatory bodies are reported within a strictly binary male-or-female gender identification. According to the most recent U.S. Census, $82 \%$ of social workers, and $72 \%$ of counselors are female (United States Department of Labor [US DOL], 2018). Marriage and family therapy is not identified as a detailed occupation in the US DOL statistics. The gender demographics of the clinicians who experienced findings of misconduct across the jurisdictions evaluated for this study reflect a split of roughly $68 \%$ female and 32\% male. Despite this current data, many assumptions about clinical gender continue to appear in the literature.

Many of the assumptions and untested hypotheses that often appear in the literature relate to sexual misconduct by clinicians. Primary among these assumptions is that most clinician sexual misconduct is committed by male practitioners. In this vein, in 1979, Pope et al. published the results of a self-report survey regarding sexual misconduct committed by psychologists. This survey was mailed to members of the American Psychological Association's (APA) psychotherapy division and inquired into psychologists' attitudes and experiences relating to sexual relationships between students and 
educators in psychology training programs and between psychotherapists and clients in clinical settings. From this study, Pope et al. reported several findings. Among these findings was that "when sexual contact occurs in the context of psychology training or psychotherapy, the predominant pattern is quite clear and simple: An older, higher status man becomes sexually active with a younger, subordinate woman" (Pope et al., 1979, p. 687).

Forty years since Pope et al.'s (1979) landmark study regarding clinician sexual misconduct, the assumption that sexual misconduct is primary committed by male clinicians against female clients continues to be articulated by many researchers (Barnett, 2014; Celenza \& Hilsenroth, 1997; Coleman \& Schaefer, 1986; Gabbard, 1994; Garfinkel et al., 1997; Grenyer, \& Lewis, 2012; Gutheil \& Gabbard, 1992; Haug, 1999; McNulty et al., 2013; Melville-Wiseman, 2016; Plaut, 2008). While Pope et al.'s findings may have represented significant relevance in their time and setting, these findings may not continue to be accurate, particularly when applied to clinical contexts beyond the practice of psychology.

In the original publication, Pope et al. (1979) did not specifically identify any limitations of his study. However, several are apparent. First, of the 1,000 potential participants contacted, the final research was based on 481 individual responses. This response represents less the $50 \%$ of the identified sample. Second, while the surveys were returned by 245 male respondents, 220 female respondents, and 16 respondents who did not identify gender, the questionnaire was intentionally mailed to 500 male and 500 female members of APA Division 29 (psychotherapy). It is unclear if this equal split is representative of the gender composition of practitioners of that division, or of the profession in general, at that time. Third, due to the high non-response rate this study experienced, the results are likely to have suffered from significant underrepresentation in data. Such underrepresentation is seen in many cases to represent the single greatest threat to the quality of survey results (Dillman et al., 2009, p. 360). 
In fact, Pope et al. (1979) mentioned this high nonresponse rate and explained that in this context the likely nonresponse bias "is toward underestimating the sexual contact" (p. 687). However, the potential impact of this bias was not sufficiently considered given the assumption that all the missing data due to nonresponses would reflect a similar gender split that is seen in the responses. Pope et al. stated that "even if all missing cases were included as cases where no sexual contact took place, gender differences would be quite large..." (p. 686). Despite these shortcomings, Pope et al.'s article continues to have a significant impact on the field, as evidenced by the frequency with which it continues to be cited.

While much research was conducted in the 1980s and 1990s with regard to clinician gender and professional sexual misconduct (Sonne \& Jochai, 2014), there is a scarcity of current research on the topic of the clinician characteristics that appear to be coincident with various types of professional misconduct. The most current studies, while dated, have been based on: (a) case studies of clinicians who received treatment subsequent to sexual misconduct with a client (Celenza \& Hilsenroth, 1997; Gabbard, 1994); (b) self-report questionnaires regarding misconduct (Garrett, 1999; Garrett \& Davis, 1998; Gartrell et al., 1986; Thoreson et al., 1993); and (c) analysis of complaints lodged with regulators and professional organizations (Grenyer \& Lewis, 2012; Symons, 2011). These studies identified a wide range of variables that correlate with charges or findings of professional misconduct.

Despite the variability in research results, gender is often identified as a critical component. Additionally, some studies that appear to have been conducted in order to identify correlations between clinician sexual identity and misconduct may be misapplied to perpetuate harmful stereotypes. Among the identified sexual identity characteristics were homosexuality (Garrett, 1999; Thoreson et al., 1993) and "perceived femininity" (Thoreson et al., 1993, p. 432) as measured by the Male Role Norm Scale (Thompson \& Pleck, 1987). Other studies have produced results that may continue to be valid. The characteristics identified in these studies include personal stressors and emotional distress (Celenza \& 
Hilsenroth, 1997; Thoreson et al., 1993); maladaptive personality traits (Celenza \& Hilsenroth, 1997), and being a male clinician with female clients (Gartrell et al., 1986; Symons, 2011). Similar research has also been conducted to investigate the types and prevalence of professional misconduct that is committed.

Types of misconduct that lead to sanctions are generally investigated and reported by profession. While there exists very little data regarding misconduct committed by marriage and family therapists, a large corpus of data with regard to misconduct by social workers and licensed counselors has been generated in the professional literature. Further, within this corpus of literature, there is almost no information about the relationship between gender and types of professional misconduct for any of the clinical professions.

Specifically, there is virtually no published research investigating correlations between gender and professional misconduct committed by licensed marriage and family therapists. In fact, the lack of research regarding this topic was recently noted in the Journal of Marital and Family Therapy (Coy et al., 2016). Coy et al. stated "Despite the necessity of upholding ethical and legal standards, there is little research on [marriage and family] therapist unprofessional conduct" (p. 139). While little is known regarding professional misconduct among marriage and family therapists, some research is beginning to emerge.

Despite this lack of data, there are two relevant studies that contained investigations into professional misconduct committed by licensed marriage and family therapists. The authors of one study of self-reported professional and personal behaviors of marriage and family therapists reported a direct relationship between the risk of potential misconduct and years of clinical experience (McLaurin et al., 2004). The authors of a second study surveyed MFT perceptions relating to the integrity and academic honesty underlying published marriage and family therapy research (Brock et al., 2009). While 
McLaurin et al. (2004) collected data regarding the gender demographics of respondents to their study, neither study applied gender as a research variable.

The third study employed a phenomenological methodology to investigate the experiences of 10 marriage and family therapists (six female and four male) who had been officially accused of professional misconduct (Coy et al., 2016). Coy et al. identified five existential themes relating to the MFTs' experiences, yet none of the themes were identified as being related to the gender of the MFT. Aside from these three studies, very little is known about professional misconduct committed by marriage and family therapists, and no researchers to date have analyzed gender differences with respect to marriage and family therapist misconduct. Such information is also lacking for other allied mental health professions.

Many researchers have investigated misconduct and the social work discipline. Some of these studies have included analysis of complaints lodged against social workers to chapter committees on inquiry of the National Association of Social Workers (NASW; Berliner, 1989), evaluation of malpractice claims filed thorough the NASW insurance trust (Reamer, 1995), and examination of complaints lodged with the NASW ethics board against social worker members of the NASW (Strom-Gottfried, 2000). Overall, the existing research provides information relating to categories of misconduct and the ranking of these categories. However, no researchers have investigated the relationship between gender and misconduct. Researchers focusing on this topic with licensed counselors have returned results that are similar to what is seen with social workers.

There have been several systematic analyses conducted regarding types of misconduct committed by licensed counselors (Even \& Robinson 2103; Neukrug et al., 2001; Symons et al., 2011). Of these, only one addressed gender as a research variable. In this recent UK study, Symons et al. examined ethical complaints made to the British Association for Counseling and Psychotherapy (BACP) between 1998 to 2007 and categorized the complaints by type. Among the research findings of this 
study were that $46 \%$ of the complaints were made against male practitioners and $54 \%$ were made against female practitioners. While the authors were unable to obtain data regarding the gender split among all members of the BACP, they surmised that male membership made up of less than $17 \%$ of total BACP membership. The authors also recommended further research into this finding (Symons et al., 2011). Analysis of professional misconduct from other allied mental health professions, including licensed psychologists, reflect a similar absence of gender data.

Given the aforementioned gaps in the literature on misconduct, two research questions were designed to guide this study. The first research question was: Among clinicians adjudicated for professional misconduct, what are the prevalence rates across the control variables in the study? The second research question was: Among clinicians adjudicated for professional misconduct, what is the relationship of the control variables (a) gender, (b) years of experience, (c) geographical region, and (d) type of license to the criterion variable of each word group category?

Method

\section{Design}

This study employed a retrospective cross-sectional study (Parker \& Berman, 2016) to analyze archival data. Archival data of records of the final determinations of disciplinary actions pertaining to clinicians sanctioned by state regulatory boards were collected from through access to publicly available online databases.

The records considered in this study were limited to those of licensed counselors, marriage and family therapists, and social workers. Records of misconduct pertaining to licensed psychologists were excluded for three primary reasons. First, while many (but not all) states have joint regulatory boards that oversee the professional practice of licensed counselors, marriage and family therapists, and social workers (e.g., Arizona, Indiana, Ohio, South Carolina, Washington), no state regulatory boards jointly regulate licensed psychologists along with these other clinical credentials. Second, in many states the 
same or similar laws and regulations apply to licensed counselors, marriage and family therapists, and social workers (e.g., Arizona, Indiana, Ohio, South Carolina, Washington). In every state, licensed psychologists are regulated by laws and regulations separate and distinct from those that regulate licensed counselors, marriage and family therapists, and social workers. Third, while much research has been conducted relating to misconduct committed by psychologists over the past several decades, much less is known about misconduct that is committed by the master's degree level clinicians. Addressing that lack of existing research was a primary focus of this study.

There were four control variables and six criterion variables used in the study. The control variables included: (a) gender (nominal), (b) years of experience (continuous), (c) geographical region (West, Midwest, South \& Northeast), type of license (licensed counselor, social worker, marriage, and family therapist). The continuous criterion variables included word counts for the following linguistic categories: (a) family words, (b) substance words, (c) finance words, (d) sex words, (e) friend words, and (f) recordkeeping words.

G*Power 3.1 was employed for power analysis (Faul et al., 2009). The effect size was drawn from a study on the relationship of demographic and social factors to ethical decision making in health professionals (Rajiah \& Venaktaraman, 2019). The average Cohen's $d$ reported in this study $(d=.35)$ was converted into the Cohen's $f^{2}$ needed for a multiple regression power calculation. The input parameters were as follows: (a) test family: $\mathrm{F}$ tests; (b) statistical test: linear multiple regression: fixed model, $R^{2}$ deviation from zero; (c) type of power analysis: a priori: compute required sample size, given $\alpha$, power, and effect size; (d) $f^{2}=0.0324$; (e) power $(1-\beta$ err probability) $=0.80$, (f) $\alpha=.0001$; and (g) number of predictors $=4$. The output included a sample size of 911 words in the corpus of final findings of misconduct and an actual power of 0.80 . 


\section{Participants}

The analysis was conducted using records of the final determinations of disciplinary actions pertaining to clinicians sanctioned by state regulatory boards. The demographic variables assessed for each subject (sanctioned clinician) included gender, years of experience at the time of the finding of misconduct, geographical region of practice, and type of license. The analyzed documents were collected from state regulatory boards through access to publicly available online databases. No attempt was made to collect documents from states that do not make such documents available to the general public through internet access.

In order to collect documents from a representative sample of regulatory boards, the following procedure was used. First, the 50 United States were divided into the four regional divisions used by the United States Census Bureau (2020). Second, the states in each U.S. Census region were randomized using an online list randomizer tool (Randomness and Integrity Services Ltd., n.d.). This tool generates a randomized arrangement of the items of any inputted list. This randomization is created through an application of the true random nature of atmospheric noise (Randomness and Integrity Services Ltd., n.d.).

The websites for the regulatory boards for each state within each randomized list of U.S. Census regions were then accessed online in order. If discipline records were not publicly available for the identified state, the regulatory board websites for the next state in the randomized list was accessed. This process was completed until records were obtained from one state in each U.S. Census region. Due to the low number of records relating to discipline for marriage and family therapists, this process was completed a second time for records relating to marriage and family therapists only.

In total, 520 documents representing 509 individuals were collected. The counts for documents and individuals do not match because 10 individuals were duplicated for analysis (i.e., nine clinicians held two licenses and one clinician held three). By census region, the adjudication records count was 
Northeast $n=36(7 \%)$, Midwest $n=179(34 \%)$, South $n=54(10 \%)$, and West $n=251(48 \%)$. For the northeast states, the adjudication records count was Connecticut $n=26(5 \%)$ and New Jersey $n=10$ (2\%). With regard to the midwestern states, the count was Ohio $\mathrm{n}=166(32 \%)$ and Indiana $n=13(3 \%)$. In terms of the southern states, the count was South Carolina $n=46(9 \%)$ and Kentucky $n=8(2 \%)$. In reference to the western states, the count was Arizona $n=236(45 \%)$ and Washington $n=15(3 \%)$.

Those 520 documents represent the following makeup with regard to license type. For marriage and family therapists, the adjudication records count was Connecticut $n=9(2 \%)$, New Jersey $n=10$ (2\%), Ohio $n=1(<1 \%)$, Indiana $n=7(1 \%)$, South Carolina $n=1(<1 \%)$, Kentucky $n=8(2 \%)$, Connecticut $n$ $=9(2 \%)$, New Jersey $n=10(2 \%)$, Arizona $n=10(2 \%)$, Washington $n=13(3 \%)$. For licensed counselors, the adjudication records count was Connecticut $n=6(1 \%)$, New Jersey $n=0(0 \%)$, Ohio $n=65(13 \%)$, Indiana $n=0(0 \%)$, South Carolina $n=15(3 \%)$, Kentucky $n=0(0 \%)$, Arizona $n=148(29 \%)$, Washington $n$ $=13(3 \%)$. For social workers, the adjudication records count was Connecticut $n=11(2 \%)$, New Jersey $n$ $=0(0 \%)$, Ohio $n=100(19 \%)$, Indiana $n=6(1 \%)$, South Carolina $n=30(6 \%)$, Kentucky $n=0(0 \%)$, Arizona $n=78(15 \%)$, Washington $n=0(0 \%)$.

With regard to license type and gender, the adjudication records count for licensed counselors was female $n=158$, male $n=75$. For marriage and family therapists, adjudication records count was female $n=36$, male $n=22$. For social workers, adjudication records count was female $n=152$, male $n=$ 64.

Gender was assessed through the demographic information provided by the pertinent state regulatory board. Where such information was incomplete or missing, gender was determined based on the use of masculine or feminine personal pronouns to refer to the clinician within the discipline document. Credential type was determined through the demographic information provided by the pertinent state regulatory board. Years of experience at the time of the finding of misconduct was determined through the demographic information provided by the pertinent state regulatory board. 


\section{Corpus}

\section{Register, Scope, and Sources}

The register for this corpus is legal writing, and the subregister is state licensure board misconduct findings of fact. In terms of scope, only final findings of professional legal or ethical misconduct dated between January 1, 2009 and December 31, 2018 were collected. 2009 was established as the start date because a significant number of states do not make records prior to 2009 available online. The following types of findings were specifically excluded from collection and analysis:

- determinations that were purely regulatory in nature (e.g., failure to pay license renewal fees or failure to document continuing education) unless there was also another related finding of misconduct

- determinations that were based solely on medical, physical, or mental impairment unless there was also another related finding of misconduct

- determinations based on state or federal criminal convictions unrelated to professional practice

- determinations based solely on misconduct that was originally adjudicated in another jurisdiction

- determinations relating to clinicians who held credentials below fully independent practice, including intern, associate, and trainee credentials

Thus, findings relating solely to regulatory violations, eligibility for licensure, and medical or mental impairment were excluded. The final findings were then collected and the section of each document consisting of a description of the events that led to the findings of misconduct (e.g., the findings of fact, or the stipulated facts) was identified. In total, 509 documents were collected. Of those 509 documents, nine represented clinicians who held two licenses, and one represented a clinician who held three 
psychotherapy licenses. The corpus of 509 documents contains 218,993 tokens, 10,610 types, and 8,514 lemmas.

\section{Preprocessing}

The original source documents were collected in either Adobe Portable Document Format (.pdf) or Microsoft Word (.docx) format. The .pdf documents were converted to Word format. The contents of each .docx document was reviewed. The text containing a description of the events that led to the finding of misconduct was identified in each document. The contents of each document other than the identified description of the events that led to the finding of misconduct were removed from the document. Some examples of such removed contents include administrative and procedural language, description of sanctions, and appellate rights. Each edited document then contained only the text description of the events that led to the finding of misconduct. The edited .docx documents were then converted to ASCII text only (.txt) format. These final .txt documents formed the corpus.

\section{Measures}

\section{Gender}

The genders were dummy coded as: female $=1$, and male $=2$. Of the 520 documents collected, the gender representation of the subjects of those documents was female $n=353$ (68\%), male $n=167$ (32\%). For female clinicians, the adjudication records count by license type was marriage and family therapy $n=35(7 \%)$, social work $n=157(30 \%)$, and licensed counselor $n=161(31 \%)$. For the male clinicians, the adjudication records count by license type was marriage and family therapy $n=24(5 \%)$, social work $n=68(13 \%)$, and licensed counselor $n=75(14 \%)$.

\section{Gender Proportion}

Gender proportion of clinicians was drawn from U.S. Department of Labor data (U.S. DoL;

United States Department of Labor [US DOL], 2018). The U.S. DoL reports gender statistics as the total number of male and female social workers, and counselors. With regard to the U.S. DoL, the counselor 
category includes both licensed counselors and marriage and family therapists. These numbers are not reported separately.

\section{Years of Practice}

Years of practice at the time of a finding of misconduct was a continuous variable, ranging from 1 to 37.

License Type

license type was a nominal variable with three categories: licensed counselor (Coun), social workers (SW), and marriage of family therapists (MFT). For the purpose of regression analyses these three categories were converted into two variables and binomialized and dummy coded as follows: (a) LicRe, 1 (Coun) = 0; $2(\mathrm{MFT})=1 ; 3(\mathrm{SW})=0$, and (b) LicRe2, 1 (Coun) = 0; $2(\mathrm{MFT})=0 ; 3(\mathrm{SW})=1$.

\section{Geographic Region}

Geographic region consisted of the four U.S. census regions (U.S. Census Bureau, 2020). For the purpose of regression analyses, these four nominal categories were converted into three variables and binomialized and dummy coded as follows: (a) RegRe11, 1 (Northeast) $=0,2$ (Midwest) $=1,3$ (South) = 0, 4 (West) = 0; (b) RegRe12, 1 (Northeast) = 0, 2 (Midwest ) = 0, 3 (South) = 1, 4 (West) = 0; (c) $\operatorname{RegRe13,~}$ 1 (Northeast) $=0,2$ (Midwest $)=0,3($ South $)=0,4($ West $)=1$.

\section{Word Categories Related to Professional Misconduct}

The challenges associated with coding types of misconduct in final findings of professional misconduct may be one of the significant barriers to research on this topic. While potential issues relating to the interrater reliability of such coding could be addressed, several significant challenges persist. First, findings of professional misconduct are often based on an ongoing course of conduct rather than one discrete event. Second, there is wide variation in how various state regulatory boards report what standard or rule was violated. Third, while many standards of professional conduct are 
similar across various states, individual state laws and regulations vary such that there is no overall consensus on categories or types of misconduct.

Therefore, rather than to attempt a process of subjectively coding the final findings of misconduct for misconduct type, an inferential linguistic content analysis was determined to provide a more accurate, albeit less direct, process to identify the contextual content of the findings of misconduct. In all cases, the final findings of misconduct contain a description of the underlying facts and circumstances of the misconduct are provided in the findings of fact or similar.

This study used a descriptive approach to compare thematic content of the final determinations by comparing word frequencies within six categories of word counts between groups. These word categories include family, finances, friends, recordkeeping, sexuality, and substances. The word lists for family, finances, friends, and sexuality were based on pre-existing wordlists in the Linguistic Inquiry and Word Count [LIWC] 2015 dictionary (Pennebaker Conglomerates Incorporated, 2015). This LIWC 2015 dictionary does not contain pre-existing wordlists for recordkeeping or substances. The final form or each of the six categories was created through collection of terms found in the APA PsychNet Thesaurus and the Medical Subject Headings (MeSH) vocabulary thesaurus used for indexing articles for PubMed MedLine (National Institutes of Health [NIH], 2015). For the complete list of terms in each category, see Blinded for Review (2020b).

\section{Apparatus}

The text analysis was conducted through the use of the LIWC word count process. LIWC software identifies and categorizes words that capture different emotions, thinking styles, and social concerns (Pennebaker Conglomerates Incorporated, 2015). The word count results were assessed for the six identified categories of terms from the LIWC dictionaries. The LIWC dictionaries and word count process have been validated through multiple studies across various disciplines (Baggott et al., 2015; Bonfils et al., 2016; Donohue et al., 2014; Egnoto \& Griffin, 2016; Zhao et al., 2016). 


\section{Data Analysis}

In terms of the first question, frequency rates and rankings were calculated. With regard to the second research question, relationships between variables were evaluated through a multiple linear regression analysis using a forced entry method. With this method, the control variables are all added to the model in one step. A single regression equation is then calculated for all the control variables. This entry approach was selected as the most efficient process by which to evaluate the regression model (Draper \& Smith, 2014). The significance level was set at .05. All analyses were conducted using Microsoft Excel.

\section{Results}

In terms of the first research question, the descriptive statistics for the control variables were as follows. With regard to gender, female $n=347$ (68\%), and male $n=162$ (32\%). Regarding license type, marriage and family therapy $n=58(11 \%)$, social work $n=217(43 \%)$, and licensed counselor $n=234$ (46\%). For geographic region, West $n=249$ (49\%), Midwest $n=171(34 \%)$, South $n=54(11 \%)$, Northeast, $n=35(7 \%)$. The mean number of years in practice at the time of the finding of misconduct was 11.4 with a range from one to 37 and a standard deviation of 7.3.

With regard to the second research question, a correlation matrix of all variables can be found in Table 1. Between control and criterion variables, there were seven correlations that were significant at the 0.1 level. Using the $r$ as an effect size, the strength of all of these correlations is small (Cohen, 1988). In reference to the multiple regression portion of this research question, four of the six analyses produced statistically significant results. The effect sizes for the significant results ranged from very weak to weak (Moore et al., 2013). Details concerning the statistically significant regression results can be reviewed in Table 2. The complete regression results are available online (Blinded for Review, 2020a). 


\section{Discussion}

This study was designed to examine word usage in final findings of misconduct among clinicians adjudicated for professional misconduct. The linguistic inquiry and word count (LIWC) software was used to analyze linguistic and psychological processes of the corpus. Results of this study inform educating, training, supervising, and regulating clinicians with regard to professional misconduct.

The results from the first research question demonstrate a wide variation of prevalence rates across the control variables in the study including gender, licensed type, years of professional practice, and region. Specifically, the gender split among clinicians disciplined for professional misconduct is reflective of the U.S. Department of Labor data on the gender split among all clinicians. One explanation for these results is that there is a similarity in the rates of misconduct that lead to final findings of misconduct regardless of clinician gender or license type. An alternative explanation for these results may be that the prevalence of reports and the prevalence of final findings of misconduct are mediated by some other non-identified variable. The former explanation for these results appears to be most likely as it is consistent with the lack of any current systematic data connecting these clinician demographics to a higher prevalence of misconduct.

The results of the second research question suggest a relationship between the demographic variables and the word groupings. Given that regression analysis is, by nature, based on a bidirectional correlation, no directional causation can be determined (Lehmann, 1998). For instance, gender was related to both family and finance words. One potential explanation for these findings is that variation in the practice setting - for example, work with families and children - may be related to clinician gender. This practice setting may then result in a higher prevalence of words relating to that practice setting occurring in the final findings of misconduct. Another potential explanation is that there is variation in the underlying causes of professional misconduct relating to family and social relationships is based on clinician gender. Between the former and the latter, the former is most likely driving the results given 
the lack of any current research data demonstrating a direct connection between clinician gender and misconduct relating to family relationships.

Another set of relationships that appeared were the five related to years of practice. These relationships were with (a) family, (b) finance, (c) sex, (d) friend, and (e) recordkeeping words. Three plausible explanations for why years of practice was so influential can be posited. First, it is possible that the rates of commission of acts that lead to final findings of unprofessional conduct increase as clinicians who progress in their professions become less involved in receiving active supervision and consultation. Second, these results may be reflective of a decrease in the rates of commission of acts that lead to final findings of unprofessional conduct due to increased knowledge and skill as clinicians progress in their professions. Third, it is possible that these results are reflective of an increase in underlying misconduct caused by developmental changes to legal and ethical standards that are better applied by more recently trained clinicians. Among these three, the most likely is the first explanation. A connection between the increase in occurrences of misconduct and a lack of supervision and consultation is consistent with emerging research regarding marriage and family therapists (Coy et al., 2016; McLaurin et al., 2004). This explanation is also more compelling given the distribution of findings of professional misconduct in significant numbers across all stages of professional practice.

No relationship was found between (a) recordkeeping words and any of the control variables other than years of practice, or (b) any of the criterion variables and geographic region or license type. Thus, it would appear that the types of professional misconduct engaged in by clinicians may be mediated by the amount of time those clinicians have been in the profession, and to a lesser extent, by clinician gender, but not by geographic region or license type. One likely explanation for the obtained results is that types of professional misconduct engaged in by clinicians do not vary based on geographic region or license type. Another potential explanation for these results is that while there does exist some relationship between clinician misconduct and license type or geographic region, as well as a 
relationship between the control variables and misconduct related to recordkeeping, these relationships were simply not identified in this analysis. Between the former and the latter, the former is most likely driving the results given the lack of any current research supporting a direct connection between clinician misconduct and license type or geographic region.

Four limitations to this study should be considered. First and foremost, the analyzed data directly relates to misconduct that has been adjudicated and substantiated by state level regulators. It is unclear to what extent that correlates with the actual occurrence of professional misconduct. Many factors may result in a wide disparity between misconduct that occurs and misconduct that is sanctioned.

Second, a closed vocabulary approach was employed for this study to identify misconduct. In this closed vocabulary process, word lists were constructed based on terms that are determined by the researcher to be indicative of an identified underlying theme. While a closed vocabulary approach can be a productive way to conduct a thematic linguistic inquiry, it has several inherent limitations. Some of these limitations can include errors in measurement based on differences in a single word's meaning or use across different contexts, and limitations based on the assumptions and preconceptions that underly the constructed word list (Kern et al., 2016). As an alternative, an open vocabulary approach makes use of a vast corpus of text to automate the building of word lists based on observed relationships between vocabulary, phrases, and themes in the corpus itself (Schwartz et al., 2013). As such, an open vocabulary approach is more likely to provide unanticipated results. Further related studies using an open vocabulary approach would complement the present study.

Third, in every case, the state regulatory boards that reported on misconduct identified practitioners as either male or female. There were no cases of any regulatory body identifying gender in any manner other than a binary female or male identity. Thus, the gender reported by the state regulatory boards may not accurately correspond with the clinician's gender identity in all cases. Lastly, 
clinician cultural, racial, and ethnic identity is not reported by any of the assessed state boards and was thus not included in this study. Due to this specific lack of data, the cultural context of professional misconduct remains unevaluated.

This study presents implications in three areas: (a) research, (b) clinical practice, and (c) the education and supervision of clinicians. In terms of research, since many of the traditionally held assumptions regarding gender correlation with professional misconduct appear to be invalid, alternative factors should be investigated. Some of these factors that correlate with professional misconduct include burnout, ineffective clinician self-care, a lack of professional support and consultation, and inadequate training and supervision (Barnett, 2014; Simionato et al., 2019). Further, racial, ethnic, and cultural identity generally is not reported by state boards; thus, it is unclear if these demographic variables would or would not correlate with professional misconduct. Further research in this area would help to clarify that question.

With regard to clinical practice, the obtained results question the long-standing assumption that one primary demographic variable-namely, clinician gender-puts a clinician at risk of professional misconduct. Second, since findings of misconduct were observed to occur in significant numbers at all points throughout clinicians' professional lives, the is clear that of ongoing consultation throughout a clinician's career, rather than consultation being needed exclusively in the early stages of clinician development is crucial . Similarly, since the type of profession misconduct committed does not appear to be related to years of practice, ongoing training and education relating to professional ethics among clinicians at various stages of their careers is appropriate.

Concerning supervision, the implications emerging from the results are two-fold. First, the lack of any identified relationship between the control variables and license type supports the viability of providing similar supervision regarding ethical practice to supervisees across a range of license types. Specifically, for clinicians in agency or group practice settings, these results support the appropriateness 
for marriage and family therapists to participate in supervision and consultation regarding ethical issues along with licensed counselors and social workers. Second, the observed gender split among clinicians disciplined for all types of professional misconduct is reflective of the gender split among all clinicians. Therefore, because clinician gender does not appear to be related to determinations of sexual professional misconduct, the need for all clinicians to recognize a range of factors that may lead to professional misconduct and to remain vigilant about maintaining ethical practices is highlighted. Lastly, this study provides implications for education in the clinical professions. Primarily, no relationship was identified between any of the control variables and geographic region or license type. Therefore, it is likely that similar types of professional misconduct occur in the clinical professions regardless of license type and regardless of geographic region. This finding supports a rationale for a similar curriculum for instruction in professional ethics across the clinical professions. Thus, educational materials and curricula developed for one license type could appropriately be used in the training of other license types. Similarly, this finding also supports the development of curriculum for instruction in professional ethics that is consistent across geographic regions. 


\section{References}

American Psychological Association. (2016). PsychNet thesaurus [Data set]. http://www.apa.org/pubs/databases/psycnet/index.aspx

Baggott, M. J., Kirkpatrick, M. G., Bedi, G., \& de Wit, H. (2015). Intimate insight: MDMA changes how people talk about significant others. Journal of Psychopharmacology, 29(6), 669-677. https://doi.org/10.1177/0269881115581962

Barnett, J. E. (2014). Sexual feelings and behaviors in the psychotherapy relationship: An ethics perspective. Journal of Clinical Psychology, 70(2), 170-181. https://doi.org/10.1002/jclp.22068

Berliner, A. K. (1989). Misconduct in social work practice. Social Work, 34(1), 69-72. https://www.jstor.org/stable/23715623

Bonfils, K. A., Luther, L., Firmin, R. L., Lysaker, P. H., Minor, K. S., \& Salyers, M. P. (2016). Language and hope in schizophrenia-spectrum disorders. Psychiatry Research, 245, 8-14. https://doi.org/10.1016/j.psychres.2016.08.013

Brock, G. W., Whiting, J. B., Matern, B., \& Fife, S. T. (2009). Integrity of the marriage and family therapy research literature: Perceptions and recommendations. Journal of Marital and Family Therapy, 35(2), 248-252. https://doi.org/10.1111/j.1752-0606.2009.00109.x

Celenza, A. M. (2006). Sexual boundary violations in the office When is a couch just a couch? Psychoanalytic Dialogues, 16(1), 113-128. https://doi.org/10.2513/s10481885pd1601 7

Celenza, A. M., \& Hilsenroth, M. (1997). Personality characteristics of mental health professionals who have engaged in sexualized dual relationships: A Rorschach investigation. Bulletin of The Menninger Clinic, 61(1), 90-107. Available from https://www.guilford.com/journals/Bulletin-ofthe-Menninger-Clinic/Eric-Storch/00259284 
Coe, R. (2002). It's the effect size, stupid: What effect size is and why it is important. Paper presented at the Annual Conference of the British Educational Research Association, University of Exeter, England. http://www.leeds.ac.uk/educol/documents/00002182.htm

Cohen, J. (1988). Statistical power analysis for the behavioral sciences. L. Erlbaum Associates.

Coleman, E., \& Schaefer, S. (1986). Boundaries of sex and intimacy between client and counselor. Journal of Counseling \& Development, 64(5), 341-344. https://doi.org/10.1002/j.15566676.1986.tb01128.x

Coy, J. S., Lambert, J. E., \& Miller, M. M. (2016). Stories of the accused: A phenomenological inquiry of MFTs and accusations of unprofessional conduct. Journal of Marital and Family Therapy, 42(1), 139-152. https://doi.org/10.1111/jmft.12109

Dillman, D. A., Smyth, J. D., \& Christian, L. M. (2009). Internet, mail, and mixed-mode surveys: The tailored design method. John Wiley \& Sons.

Donohue, W. A., Liang, Y., \& Druckman, D. (2014). Validating LIWC dictionaries: The Oslo I Accords. Journal of Language and Social Psychology, 33(3), 282-301. https://doi.org/10.1177/0261927X13512485

Draper, N. R., \& Smith, H. (2014). Selecting the "best" regression equation. In N. R. Draper \& H. Smith (Eds.), Applied regression analysis (pp. 327-368). John Wiley \& Sons. https://doi.org/10.1002/9781118625590.ch15

Egnoto, M. J., \& Griffin, D. J. (2016). Analyzing language in suicide notes and legacy tokens. Crisis, 37(2), 140-147. https://doi.org/10.1027/0227-5910/a000363

Ellis, P. D. (2009). Effect size calculators. http://www.polyu.edu.hk/mm/effectsizefaqs/calculator/calculator.html

Ellis, P. D. (2010). The essential guide to effect sizes: Statistical power, meta-analysis, and the interpretation of research results. Cambridge University Press. 
Even, T. A., \& Robinson, C. R. (2013). The impact of CACREP accreditation: A multiway frequency analysis of ethics violations and sanctions. Journal of Counseling and Development, 91(1), 26-34. https://doi.org/10.1002/i.1556-6676.2013.00067.x

Faul, F., Erdfelder, E., Buchner, A., \& Lang, A.-G. (2009). Statistical power analyses using G*Power 3.1: Tests for correlation and regression analyses. Behavior Research Methods, 41, 1149-1160. https://doi.org/10.3758/BRM.41.4.1149

Garrett, T. D. \& Davis, J. D. (1998). The prevalence of sexual contact between British clinical psychologists and their patients. Clinical Psychology \& Psychotherapy, 5(4), 253-263. https://doi.org/10.1002/(SICI)1099-0879(199812)5:4<253::AID-CPP171>3.0.CO;2-4

Gabbard, G. O. (1996). Lessons to be learned from the study of sexual boundary violations. American Journal of Psychotherapy, 50(3), 311-322. https://doi.org/10.1176/appi.psychotherapy.1996.50.3.311

Garfinkel, P. E., Bagby, R. M., Waring, E. M., \& Dorian, B. (1997). Boundary violations and personality traits among psychiatrists. Canadian Journal of Psychiatry, 42(7), 758-763. https://doi.org/10.1177/070674379704200709

Garrett, T. D. (1999). Sexual contact between clinical psychologists and their patients: Qualitative data. Clinical Psychology \& Psychotherapy, 6(1), 54-62. https://doi.org/10.1002/(SICI)10990879(199902)6:1<54::AID-CPP181>3.0.CO;2-S

Garrett, T. D., \& Davis, J. D. (1998). The prevalence of sexual contact between British clinical psychologists and their patients. Clinical Psychology \& Psychotherapy, 5(4), 253-263. https://doi.org/10.1002/(SICI)1099-0879(199812)5:4<253::AID-CPP171>3.0.CO;2-4

Gartrell, N., Herman, J., Olarte, S., Feldstein, M., \& Localio, R. (1986). Psychiatrist-patient sexual contact: Results of a national survey. I: Prevalence. American Journal of Psychiatry, 143(9), 1126-1131. https://doi.org/10.1176/ajp.143.9.1126 
Grenyer, B. L., \& Lewis, K. L. (2012). Prevalence, prediction, and prevention of psychologist misconduct. Australian Psychologist, 47(2), 68-76. https://doi.org/10.1111/j.1742-9544.2010.00019.x

Gutheil, T. G., \& Gabbard, G. O. (1992). Obstacles to the dynamic understanding of therapist-patient sexual relations. American Journal of Psychotherapy, 46(4), 515-525. https://doi.org/10.1176/appi.psychotherapy.1992.46.4.515

Haug, I. E. (1999). Boundaries and the use and misuse of power and authority: Ethical complexities for clergy psychotherapists. Journal of Counseling \& Development, 77(4), 411-417. https://doi.org/10.1002/i.1556-6676.1999.tb02467.x

Hauke, J., \& Kossowski, T. (2011). Comparison of values of Pearson's and Spearman's correlation coefficients on the same sets of data. Quaestiones Geographicae, 30(2), 87-93. https://doi.org/10.2478/v10117-011-0021-1

Hochster, H. S. (2008). The power of " $p$ ": On overpowered clinical trials and "positive" results. Gastrointestinal Cancer Research: GCR, 2(2), 108-109. https://www.ncbi.nlm.nih.gov/pmc/articles/PMC2630828/

Kern, M. L., Park, G., Eichstaedt, J. C., Schwartz, H. A., Sap, M., Smith, L. K., \& Ungar, L. H. (2016). Gaining insights from social media language: Methodologies and challenges. Psychological Methods, 21(4), 507-525. http://doi.org/10.1037/met0000091

Lehmann, E. L. (1998). Nonparametrics: Statistical methods based on ranks. Springer. Lenhard, W., \& Lenhard, A. (2015). Calculation of effect sizes. http://www.psychometrica.de/effect size.html

Lipsey, M. W., \& Wilson, D. B. (1993). The efficacy of psychological, educational, and behavioral treatment: Confirmation from meta-analysis. American Psychologist, 48(12), 1181-1209. https://doi.org/10.1037/0003-066X.48.12.1181 
McLaurin, S. L., Ricci, R. J., \& McWey, L. M. (2004). A developmental perspective of marriage and family therapist's ethical principles: Support for the practitioner-ethics relationship model. Contemporary Family Therapy, 26(3), 293-306. https://doi.org/10.1023/B:COFT.0000037916.88984.b1

McNulty, N., Ogden, J., \& Warren, F. (2013). 'Neutralizing the patient': Therapists' accounts of sexual boundary violations. Clinical Psychology and Psychotherapy, 20(3), 189-198. https://doi.org/10.1002/cpp.799

Melville-Wiseman, J., (2016). The sexual abuse of vulnerable people by registered social workers in England: An analysis of the Health and Care Professions Council fitness to practise cases. British Journal of Social Work, 46(8), 2190-2207. https://doi.org/10.1093/bjsw/bcw150

Meyers, L. (2017, October 25). Making the counseling profession more diverse. Counseling Today, 60(5), 32-48. https://ct.counseling.org/2017/10/making-counseling-profession-diverse/

Michel, R. E., Hall, S. B., Hays, D. G., \& Runyan, H. I. (2013). A mixed methods study of male recruitment in the counseling profession. Journal of Counseling \& Development, 91(4), 475-482. https://doiorg/10.1002/j.1556-6676.2013.00120.x

Mittendorf, S. H., \& Schroeder, J. (2004). Boundaries in social work: The ethical dilemma of social worker-client sexual relationships. Journal of Social Work Values and Ethics, 1(1), 2-9. https://jswve.org/download/2004-1/JSWVE-Fall-2004-Complete.pdf

Moore, D. S., Notz, W. I, \& Flinger, M. A. (2013). The basic practice of statistics (6th ed.). W. H. Freeman and Company.

Neukrug, E., Milliken, T., \& Walden, S. (2001). Ethical complaints made against credentialed counselors: An updated survey of state licensing boards. Counselor Education and Supervision, 41(1), 57-70. https://doi.org/10.1002/i.1556-6978.2001.tb01268.x 
Nortje, N. A., \& Hoffmann, W. A. (2015). Ethical misconduct by registered psychologists in South Africa during the period 2007-2013. South African Journal of Psychology, 45(2), 260-270. https://doi.org/10.1177/0081246315571194

Parker, R. A., \& Berman, N. G., (2016). Planning clinical research. Cambridge University Press.

Pennebaker Conglomerates, Incorporated. (2015). How does LIWC analyze language? http://liwc.wpengine.com/how-it-works/

Plaut, S. M. (2008). Sexual and nonsexual boundaries in professional relationships: Principles and teaching guidelines. Sexual \& Relationship Therapy, 23(1), 85-94. https://doi.org/10.1080/14681990701616624

Pope, K. S., Levenson, H. \& Shover, L. R. (1979). Sexual intimacy in psychology training: Results and implications on a national survey. American Psychologist, 34(8), 682-689. https://doi.org/10.1037/0003-066X.34.8.682

Rajiah, K., \& Venaktaraman, R. (2019). The effect of demographic and social factors on the decisionmaking of community pharmacists in ethical dilemmas. Journal of Research in Pharmacy Practice, 8(3), 174-177. https://doi.org/10.4103/jrpp.JRPP 1915

Randomness and Integrity Services Ltd. (n.d.). List randomizer. https://www.random.org/lists/

Reamer, F. G. (1995). Malpractice claims against social workers: First facts. Social Work, 40(5), 595-601. https://doi.org/10.1093/sw/40.5.595

Sarkar, S. P. (2004). Boundary violation and sexual exploitation in psychiatry and psychotherapy: A review. Advances in Psychiatric Treatment, 10(4), 312-320. https://doi.org/10.1192/apt.10.4.312

Schwartz, H. A., Eichstaedt, J. C., Kern, M. L., Dziurzynski, L., Ramones, S. M., Agrawal, M., Shah, A., Kosinski, M., Stillwell, D., Seligman, M. E., \& Ungar, L. H. (2013). Personality, gender, and age in the language of social media: The open-vocabulary approach. PloS One, 8(9), e73791. https://doi.org/10.1371/journal.pone.0073791 
Shipman, D., \& Martin, T. (2019). Clinical and supervisory considerations for transgender therapists: Implications for working with clients. Journal of Marital and Family Therapy, 45(1), 92-105. https://doi-org/10.1111/imft.12300

Simionato, G., Simpson, S., \& Reid, C. (2019). Burnout as an ethical issue in psychotherapy. Psychotherapy, 56(4), 470-482. https://doi-org/10.1037/pst0000261

Sonne, J. L., \& Jochai, D. (2014). The "Vicissitudes of Love" between therapist and patient: A review of the research on romantic and sexual feelings, thoughts, and behaviors in psychotherapy. Journal of Clinical Psychology, 70(2), 182-195. https://doi.org/10.1002/iclp.22069

Blinded for Review. (2020a). Non-significant regression results. https://osf.io/k6jpa/

Blinded for Review. (2020b). Professional misconduct wordlists. https://osf.io/bcj7q/

Strom-Gottfried, K. (2000). Ensuring ethical practice: An examination of NASW code violations, 1986-97. Social Work, 45(3), 251-261. https://doi.org/10.1093/sw/45.3.251

Symons, C., Khele, S., Rogers, J., Turner, J., \& Wheeler, S. (2011). Allegations of serious professional misconduct: An analysis of the British Association for Counselling and Psychotherapy's Article 4.6 cases, 1998-2007. Counselling \& Psychotherapy Research, 11(4), 257-265. https://doi.org/10.1080/14733145.2010.519044

Thompson, E. H., Jr., \& Pleck, J. H. (1987). The structure of male role norms. In M. S. Kimmel (Ed.), Changing men: New directions in research on men and masculinity (pp. 25-36). Sage.

Thoreson, R. W., Shaughnessy, P. Heppner, P. P., \& Cook S. W. (1993). Sexual contact during and after the professional relationship: Attitudes and practices of male counselors. Journal of Counseling \& Development, 71(1), 429-434. https://doi.org/10.1002/j.1556-6676.1995.tb01827.x

United States Census Bureau. (2020). Census regions and divisions of the United States. https://www2.census.gov/geo/pdfs/maps-data/maps/reference/us regdiv.pdf 
United States Department of Labor. (2019, Jan 18). Labor force statistics from the current population survey. http://www.bls.gov/cps/cpsaat11.htm

Willyard, C. (2011). Men: A growing minority? gradPSYCH Magazine, 9, 40. https://www.apa.org/gradpsych/2011/01/cover-men

Zhao, N., Jiao, D., Bai, S., \& Zhu, T. (2016). Evaluating the validity of simplified Chinese version of LIWC in detecting psychological expressions in short texts on social network services. Plos One, 11(6), e0157947. https://doi.org/10.1371/journal.pone.0157947 
Table 1

Correlation Matrix (Multinomial Variables Excluded)

\begin{tabular}{|c|c|c|c|c|c|c|c|c|c|}
\hline & & 1 & 2 & 3 & 4 & 5 & 6 & 7 & 8 \\
\hline 1 & Family & - & & & & & & & \\
\hline 2 & Substance & -0.004 & - & & & & & & \\
\hline 3 & Finance & $-0.217^{* * *}$ & $*-0.131 * *$ & - & & & & & \\
\hline 4 & Sex & $0.140 * *$ & $-0.169 * * *$ & $*-0.034$ & - & & & & \\
\hline 5 & Friend & $0.106 *$ & $-0.190 * * *$ & * 0.002 & $0.720 * * *$ & - & & & \\
\hline 6 & Recordkeeping & 0.075 & $0.105 *$ & $-0.101 *$ & $-0.202 * * *$ & $-0.287 * * *$ & - & & \\
\hline 7 & Years in Prac. & $0.126 * *$ & 0.003 & $-0.115 * *$ & ${ }^{*}-0.174 * * *$ & $-0.164 * * *$ & $0.113 *$ & - & \\
\hline 8 & Gender & $-0.107^{*}$ & -0.039 & $0.090 *$ & 0.053 & -0.001 & -0.060 & 0.082 & - \\
\hline
\end{tabular}

Note: 2 records were removed due to missing years in practice data. Thus 507 records included out of a total of 509. The following correlation statistics were used given the nature of the variables: continuous by continuous--Pearson's $r$, binomial by continuous--point-biserial $r_{\mathrm{p}-\mathrm{b}}$. 
Table 2

Regression Results

\begin{tabular}{|c|c|c|c|c|c|c|}
\hline Category & $t$ & $p$ & $F$ & $d f$ & $p$ & Adj. $R^{2}$ \\
\hline \multicolumn{7}{|l|}{ Family } \\
\hline Overall Model & & & 0.00000007 & 7, 499 & 0.057 & 0.08 \\
\hline Years in $\mathrm{P}$ & 2.218 & 0.027 & & & & \\
\hline GenRe & -2.520 & 0.012 & & & & \\
\hline LicRe1 & 2.258 & 0.024 & & & & \\
\hline LicRe2 & 0.305 & 0.760 & & & & \\
\hline RegRe1 & -0.066 & 0.947 & & & & \\
\hline RegRe2 & 0.455 & 0.649 & & & & \\
\hline RegRe3 & 2.452 & 0.015 & & & & \\
\hline \multicolumn{7}{|l|}{ Finances } \\
\hline Overall Model & & & 0.05 & 7,499 & $<.001$ & 0.014 \\
\hline Years in $\mathrm{P}$ & -2.5596 & 0.0108 & & & & \\
\hline GenRe & 2.3174 & 0.0209 & & & & \\
\hline LicRe1 & -0.3457 & 0.7297 & & & & \\
\hline LicRe2 & 1.3030 & 0.1932 & & & & \\
\hline RegRe1 & -0.3746 & 0.7081 & & & & \\
\hline RegRe2 & -0.4711 & 0.6377 & & & & \\
\hline RegRe3 & -0.1765 & 0.8600 & & & & \\
\hline \multicolumn{7}{|l|}{ Friend } \\
\hline Overall Model & & & 0.000042 & 7,499 & $<.001$ & 0.049 \\
\hline Years in $P$ & -2.924 & 0.004 & & & & \\
\hline GenRe & 0.217 & 0.828 & & & & \\
\hline LicRe1 & -0.593 & 0.553 & & & & \\
\hline LicRe2 & 1.293 & 0.197 & & & & \\
\hline RegRe1 & 0.874 & 0.383 & & & & \\
\hline RegRe2 & -0.127 & 0.899 & & & & \\
\hline RegRe3 & -0.912 & 0.362 & & & & \\
\hline \multicolumn{7}{|l|}{ Sex } \\
\hline Overall Model & & & 0.000003 & 7,499 & $<.001$ & 0.06 \\
\hline Years in $P$ & -3.1721 & 0.0016 & & & & \\
\hline GenRe & 1.4973 & 0.1349 & & & & \\
\hline LicRe1 & -0.2947 & 0.7683 & & & & \\
\hline LicRe2 & 0.6998 & 0.4844 & & & & \\
\hline RegRe1 & 1.4227 & 0.1555 & & & & \\
\hline RegRe2 & -0.5475 & 0.5843 & & & & \\
\hline
\end{tabular}




\begin{tabular}{|c|c|c|c|c|c|c|}
\hline $\begin{array}{l}\text { RegRe3 } \\
\text { Substances }\end{array}$ & \multicolumn{5}{|c|}{ Substances } & \\
\hline Overall Model & & & 0.00000001 & 7,499 & 0.0003 & 0.08 \\
\hline Years in $P$ & -0.8564 & 0.3922 & & & & \\
\hline GenRe & -0.6897 & 0.4907 & & & & \\
\hline LicRe1 & 0.3919 & 0.6953 & & & & \\
\hline LicRe2 & -0.0743 & 0.9408 & & & & \\
\hline RegRe1 & -2.1741 & 0.0302 & & & & \\
\hline RegRe2 & -1.5541 & 0.1208 & & & & \\
\hline RegRe3 & 1.1704 & 0.2424 & & & & \\
\hline \multicolumn{7}{|l|}{ Recordkeeping } \\
\hline Overall Model & & & 0.00000002 & 7,499 & 0.0000 & 0.093 \\
\hline Years in $P$ & 2.4810 & 0.0134 & & & & \\
\hline GenRe & -1.3404 & 0.1807 & & & & \\
\hline LicRe1 & -1.7066 & 0.0885 & & & & \\
\hline LicRe2 & -0.9123 & 0.3620 & & & & \\
\hline RegRe1 & -0.9231 & 0.3564 & & & & \\
\hline RegRe2 & -0.9628 & 0.3361 & & & & \\
\hline RegRe3 & 1.7483 & 0.0810 & & & & \\
\hline
\end{tabular}

